\title{
AVALIAÇÃO DE MÉTODOS PARA QUEBRA DA DORMÊNCIA E PARA A DESINFESTAÇÃO DE SEMENTES DE CANAFÍSTULA (Peltophorum dubium (Sprengel) Taubert ${ }^{1}$
}

\author{
Luciana Magda de Oliveira ${ }^{2}$, Antonio Claudio Davide ${ }^{3}$ e Maria Laene Moreira de Carvalho ${ }^{3}$
}

\begin{abstract}
RESUMO - Este trabalho teve como objetivo testar a eficiência de diferentes tratamentos para quebra da dormência e desinfestação de sementes de canafístula na realização do teste de germinação. O experimento foi realizado em esquema fatorial com três lotes $\mathrm{x}$ cinco tratamentos para quebra da dormência $\mathrm{x}$ quatro tratamentos de desinfestação das sementes. As sementes utilizadas foram coletadas nos municípios de Lavras-MG, em 1986 e 1998, e em Lins-SP, em 1998. Os tratamentos para quebra da dormência foram constituídos por escarificação manual com lixa, água quente (a- fervura das sementes por 3 minutos com imersão por 24 horas, fora do aquecimento; e b- imersão das sementes em água quente por 24 horas, fora do aquecimento) e ácido sulfúrico (imersão por 15, 17, 20 e 30 minutos). Para desinfestação das sementes foram testados os tratamentos, utilizando Polyfluanide ( $0,2 \%$ por 30 minutos), Benomyl ( $0,02 \%$ por 1 minuto) e hipoclorito de sódio ( $2 \%$ por 3 minutos). Foram utilizadas quatro repetições de 25 sementes em cada tratamento. $O$ teste de germinação foi instalado sobre areia, na temperatura de $25{ }^{\circ} \mathrm{C}$, sob luz branca constante. As contagens de germinação (plântulas normais) foram realizadas diariamente. $\mathrm{O}$ tratamento de imersão das sementes de canafístula em água quente $\left(95^{\circ} \mathrm{C}\right)$ e posterior permanência na mesma água por mais 24 horas, fora do aquecimento, é eficiente na promoção da germinação, sendo prático e dispensando o uso de tratamentos de desinfestação.
\end{abstract}

Palavras-chave: Peltophorum dubium, dormência e desinfestação.

\section{EVALUATION OF METHODS FOR DORMANCY BREAKING AND DISINFESTATION OF CANAFISTULA SEEDS (Peltophorum dubium (Sprengel) Taubert - Caesalpinoideae}

\begin{abstract}
This research was carried out to test the different treatments for dormancy breaking and disinfestation of canafistula seeds. The experiment was carried out using a factorial system with three groups $x$ five treatments of dormancy breaking x four treatments of seed disinfestation. The seeds were collected in Lavras-MG in 1986 and 1998, and in Lins-SP, in 1998. The treatments used for dormancy breaking consisted of manual scarification with sand paper. The treatments used for dormancy breaking consisted of scarification with sand paper, hot water, (a-boiling the seeds for three minutes with immersion for 24 hours away from heat; and b-immersion 24 hours away from heat) and sulfuric acid (immersion for 15, 17, 20 and 30 minutes). For seed disinfestation, the treatments were tested using polyfluanide (0.2\% for 30 minutes), Benomyl (0.02\% for 1 minute) and sodium hypochlorite (2\% for 3 minutes). Four repetitions of 25 seeds were used for each treatment. The germination test was installed in sand, at $25^{\circ} \mathrm{C}$, with white light. Germination counts of normal seedlings were performed daily. The immersion of canafistula seeds in hot water $\left(95^{\circ} \mathrm{C}\right)$ and posterior permanence in the same water, away from heat, for another 24 hours is effective in promoting germination, practical and does not need disinfestation treatments.
\end{abstract}

Key words: Peltophorum dubium, dormancy, and disinfestation.

1 Recebido para publicação em 20.2.2002.

Aceito para publicação em 9.9.2003.

2 Enga.-Florestal, M.S. Doutoranda - Universidade Federal de Lavras (UFLA), Caixa Postal 37, $37200-000$ Lavras-MG. <lumagda@lavras.br>; ${ }^{2}$ Eng.-Agr., Dr. Prof. - UFLA, <acdavide@ufla.br>; ${ }^{3}$ Enga .-Agr., Dr. Profa. - UFLA, <mlaenemc@ufla.br>. 


\section{INTRODUÇÃO}

A dormência das sementes é um dos principais problemas para produção de mudas de espécies florestais nativas, principalmente de leguminosas.

Bewley \& Black (1994) reconhecem três tipos de dormência em sementes: dormência imposta pelo tegumento, dormência devido ao embrião (subdesenvolvido ou subdiferenciado) e dormência devido a substâncias promotoras e inibidoras. A dormência imposta pelo tegumento, comum em sementes da família Leguminosae, como a canafístula (Bianchetti \& Ramos, 1982), tem trazido problemas aos viveiristas na formação de mudas.

Os diversos tratamentos usados para superar esse tipo de dormência baseiam-se no princípio de dissolver a camada cuticular cerosa ou formar estrias/perfurações no tegumento das sementes, pois a sua ruptura é imediatamente seguida de embebição, o que propicia o início do processo germinativo (Bianchetti \& Ramos, 1981). Entre os tratamentos utilizados com sucesso para superação da dormência tegumentar de espécies florestais, destacam-se as escarificações mecânica e química, além da imersão das sementes em água quente. A aplicação e a eficiência desses tratamentos dependem do grau de dormência, que é variável entre diferentes espécies, procedências e anos de coleta.

Os diversos autores que trabalharam com sementes de canafístula recomendaram tratamentos diferentes para quebra de sua dormência. A dormência pôde ser superada por tratamentos com ácido sulfúrico concentrado por 30 minutos (Capelanes, 1991); 20 minutos (Guerra et al., 1982); e 4, 6 ou 8 minutos (Bianchetti \& Ramos, 1982). A escarificação mecânica também se mostrou eficiente na superação da dormência, segundo Bianchetti e Ramos (1982), Figliolia \& Silva (1982) e Guerra et al. (1982). Já Salerno et al. (1996) elegeram o tratamento de imersão das sementes de canafístula em água quente $\left(100^{\circ} \mathrm{C}\right)$ como o mais eficiente para este propósito.

Além da dormência, outro fator que dificulta a germinação de sementes de canafístula é a alta incidência de fungos. Mucci \& Lasca (1986) observaram diversos fungos presentes em sementes de canafístula, como: Phomopsis sp., Fusicoccum sp., Fusarium oxysporum, F. solani, F. moniliforme, Phoma sp., Verticillium sp., Pestalotia sp., Curvularia spp, e Drechslera spp,, os quais, segundo esses autores, podem causar danos a essas sementes.

R. Árvore, Viçosa-MG, v.27, n.5, p.597-603, 2003
De acordo com Ferreira (1989), um dos problemas mais sérios nos estudos de germinação é a grande contaminação fúngica das sementes, principalmente em testes realizados em incubadoras ou germinadores, que dão condições ideais para o desenvolvimento e a disseminação de alguns dos fungos, causando apodrecimento das sementes e dificultando o diagnóstico correto da qualidade fisiológica do lote. Tal fato demonstra a necessidade de utilização de produtos que visam a diminuição ou a eliminação destes patógenos. A recomendação de produtos que visam o tratamento de sementes de espécies florestais deve considerar a população fúngica associada e o respectivo método de aplicação.

Diante do exposto, este trabalho teve como objetivo testar a eficiência de tratamentos de quebra da dormência e de desinfestação em sementes de canafístula para testes de germinação.

\section{MATERIAL E MÉTODOS}

Os frutos de canafístula foram coletados manualmente, quando apresentavam coloração marrom, nos municípios de Lavras-MG, em 1986 (Lavras1986) e 1998 (Lavras1998), e em Lins-SP, em 1998 (Lins1998). O município de Lavras está a $920 \mathrm{~m}$ de altitude, e pela classificação de Köppen o clima da região se encontra no limite entre $\mathrm{Cwb}$ e $\mathrm{Cwa}$, caracterizando clima temperado a temperado subtropical, com estação seca de maio a setembro e chuvosa de novembro a março. A temperatura média anual é de $19,4^{\circ} \mathrm{C}$, sendo a máxima de $26,1^{\circ} \mathrm{C}$ e a mínima de $14,8^{\circ} \mathrm{C}$. Já o município de Lins-SP está a $437 \mathrm{~m}$ de altitude, com clima quente e inverno seco, com a estação chuvosa nos meses de outubro a março. A temperatura média anual é de $19,4^{\circ} \mathrm{C}$, sendo a máxima de $27,48{ }^{\circ} \mathrm{C}$ e a mínima de $22^{\circ} \mathrm{C}$ (IBGE, 1995).

Após a coleta, que foi realizada em três matrizes para cada lote, os frutos foram secos ao sol e colocados em saco de aniagem, onde, com o auxílio de um martelo de borracha, foi efetuada a extração das sementes. Em seguida, as sementes foram armazenadas em sacos de polietileno e mantidas em câmara com controle de temperatura e umidade $\left(6-9^{\circ} \mathrm{C} ; 70 \%\right.$ UR). O lote Lavras 1986 foi armazenado por 12 anos e os lotes Lavras1998 e Lins1998, por 3 meses.

Para determinação da umidade das sementes foi adotado o método da estufa, com circulação de ar a $103 \pm 2{ }^{\circ} \mathrm{C}$ por 17 horas, conforme Brasil (1992). As sementes foram quebradas dentro de um saco plástico, 
com o auxílio de um alicate, colocadas em recipientes de alumínio, pesadas e colocadas em estufa. Foram utilizadas quatro repetições para cada lote. Os resultados foram calculados com base no peso das sementes úmidas (base úmida).

Dois experimentos foram conduzidos de forma seqüencial. No primeiro efetuou-se a seleção prévia de tratamentos para quebra da dormência de sementes de canafístula. Com base nesta seleção foi realizado um segundo experimento, no qual, além da quebra de dormência também foram estudados estudou os efeitos que os métodos de desinfestação de sementes poderiam ter na germinação.

Para o primeiro experimento, sementes provenientes de dois lotes (Lavras1986 e Lavras1998) foram submetidas aos seguintes tratamentos de quebra da dormência:

a) escarificação manual (Lixa): as sementes foram lixadas (lixa $\mathrm{n}^{\circ} 60$ ), superficialmente, na região oposta ao eixo embrionário e imersas em água por 24 horas, à temperatura de $25^{\circ} \mathrm{C}$;

b) ácido sulfúrico: as sementes foram submersas em ácido sulfúrico concentrado (98\%) por 15 (Ácido 15') e 30 (Ácido 30') minutos e, a seguir, lavadas em água corrente por 1 hora e imersas em água por 14 horas, à temperatura de $25^{\circ} \mathrm{C}$ (Davide et al., 1995);

c) água quente: as sementes foram imersas em água quente $\left(95^{\circ} \mathrm{C}\right)$ e deixadas em repouso na mesma água, fora do aquecimento, por 24 horas, à temperatura de $25{ }^{\circ} \mathrm{C}$; e

d) testemunha: sementes sem tratamento para quebra da dormência.

Foram utilizadas quatro repetições de 25 sementes em cada tratamento, para ambos os lotes. Após a aplicação dos tratamentos de quebra da dormência, as sementes foram tratadas com solução de hipoclorito de sódio a $2 \%$ por 3 minutos e colocadas para germinar sobre areia a $25^{\circ} \mathrm{C}$, sob luz branca constante, conforme Oliveira (2000).

A classificação das plântulas como normais ou anormais foi realizada seguindo a descrição proposta por Alcalay e Amaral (1981), considerando normais as plântulas com todas as estruturas essenciais em perfeito desenvolvimento.

No segundo experimento, foram utilizadas sementes dos lotes Lavras1986, Lavras1998 e Lins 1998. Os tratamentos para quebra da dormência foram constituídos por:

a) ácido sulfúrico concentrado (98\%): as sementes foram submersas em ácido sulfúrico concentrado por 15 (Ácido 15'), 17 (Ácido 17') e 20 (Ácido 20') minutos $\mathrm{e}$, em seguida, lavadas em água corrente por 1 hora e deixadas imersas em água por 14 horas, à temperatura de $25{ }^{\circ} \mathrm{C}$;

b) água quente: as sementes foram imersas em água quente $\left(95^{\circ} \mathrm{C}\right)$ e deixadas em repouso, fora do aquecimento, por 24 horas, à temperatura de $25^{\circ} \mathrm{C}$ (Água I) e

c) fervura: as sementes foram fervidas por 3 minutos, deixadas em repouso nesta mesma água por 24 horas, fora do aquecimento, à temperatura de $25^{\circ} \mathrm{C}$ (Água II).

Após a utilização dos tratamentos para quebra da dormência, as sementes foram desinfestadas com os produtos: Polyfluanide 500 (Euparen) - 0,2\%/30 minutos; Benomyl 500 (Benlate) - 0,02\%/1 minuto, hipoclorito de sódio - 2\%/3 minutos e testemunha - sementes sem desinfestação.

O teste de germinação foi realizado seguindo a metodologia e a avaliação descritas para o primeiro experimento. Calculou-se o índice de velocidade de germinação (IVG), segundo Maguire (1962).

Os fungos encontrados nas sementes durante o teste de germinação foram identificados no Laboratório de Patologia de Sementes da Universidade Federal de Lavras.

Foi utilizado um esquema fatorial ( $5 \times 4 \times 3)$, com cinco tratamentos de quebra de dormência $x$ quatro tratamentos de desinfestação $\mathrm{x}$ três lotes, em delineamento inteiramente casualizado. Foram utilizadas quatro repetições de 25 sementes por tratamento.

Os dados obtidos nos dois experimentos foram transformados em arco-seno $\sqrt{ }(\mathrm{x} / 100)$ e submetidos à análise de variância. As médias dos tratamentos foram comparadas pelo teste de Tukey a 5\%, usando o programa SANEST.

\section{RESULTADOS E DISCUSSÃO}

As sementes de canafístula apresentaram graus de umidade em torno de $10 \%$ por ocasião da realização dos experimentos, com uma variação de $0,5 \%$ entre lotes.

R. Árvore, Viçosa-MG, v.27, n.5, p.597-603, 2003 
Todos os tratamentos utilizados no primeiro experimento para quebra da dormência das sementes foram eficazes em favorecer o amolecimento dos tegumentos, resultando em $0 \%$ de sementes duras, enquanto as testemunhas apresentaram 81 e $50 \%$ de sementes duras nos lotes Lavras1986 e Lavras1998, respectivamente (Quadro 1), o que demonstra a necessidade de utilização de tratamentos para quebra da dormência em sementes de canafístula.

O método Ácido 30' resultou em 100 e 97\% de sementes mortas nos lotes Lavras1986 e Lavras1998, respectivamente (Quadro 1). Estes resultados diferiram dos observados por Capelanes (1991), que indicou este tratamento como o mais eficiente na superação da dormência e promoção da germinação de sementes desta espécie, provavelmente devido ao maior grau de dormência das sementes utilizadas por este autor.

Os tratamentos Lixa, Ácido 15' e Água quente propiciaram melhores porcentagens de germinação em ambos os lotes (Quadro 1); entretanto, o tratamento Lixa apresenta o inconveniente de sua aplicação prática pela dificuldade de execução em larga escala. Além disto, os tegumentos permaneceram presos aos cotilédones das plântulas. Constata-se que o desprendimento dos cotilédones é um importante fator no desenvolvimento de plântulas normais. Cotilédones presos (temporária ou permanentemente) dentro dos tegumentos tornam-se sujeitos a vários tipos de danos (Burg et al., 1994).

Assim, os métodos que utilizam água quente e ácido sulfúrico por 15 minutos foram superiores aos demais, levando-se em conta a eficiência e praticidade, tendo sido selecionados para realização do segundo experimento. Além destes, devido ao alto grau de dormência ( $85 \%$ de sementes duras) apresentado pelo novo lote (Lins 1998), que foi acrescido para o segundo experimento, testou-se o uso de água quente e ácido sulfúrico por períodos maiores.

No segundo experimento os tratamentos para quebra da dormência (Ácido 15, 17 e 20 minutos e Água I e II) foram eficientes, uma vez que não foram observadas sementes duras após o período do teste (dados nãomostrados). Não foram observadas, também, sementes que apenas embeberam água, mas não apresentavam protrusão radicular, tendo sido constatadas somente plântulas normais, plântulas anormais e sementes mortas.

Para os três lotes utilizados, o tratamento Água II não apresentou eficiência na promoção da germinação

R. Árvore, Viçosa-MG, v.27, n.5, p.597-603, 2003 das sementes (Quadro 2). Resultados semelhantes foram obtidos por Todd-Bockarie et al. (1993) em sementes de Cassia sieberiana. Estes autores relatam que tratamentos com temperaturas quentes extremas danificam ou matam as sementes desta espécie.

Constatou-se (Quadro 2) que o tratamento Ácido 15 ' foi eficiente para os três lotes. O tratamento Ácido 20' causou a morte das sementes dos lotes mais novos, Lavras1998 e Lins1998, mas foi eficiente para o lote Lavras1986, provavelmente devido ao maior grau de dormência ( $81 \%$ de sementes duras) neste lote mais antigo, conforme havia sido observado no experimento anterior (Quadro 1). O tratamento Ácido 17 ‘ foi eficiente para o lote Lavras1986 e também para o lote Lins1998.

Esses resultados demonstram a existência de elevada variação entre graus de dormência de lotes de sementes coletados em locais diferentes dentro de um mesmo ano, bem como entre anos diferentes dentro de um mesmo local.

A eficiência do ácido sulfúrico na quebra de dormência e promoção da germinação de sementes de canafístula foi verificada por vários autores. Porém, esta eficiência foi conseguida ao utilizar diferentes tempos de imersão das sementes em ácido sulfúrico, como 30 minutos (Capelanes, 1991), 20 minutos (Guerra et al., 1982) e 4, 6 e 8 minutos (Bianchetti \& Ramos, 1981).

O tratamento Água I não diferiu estatisticamente do tratamento Ácido 15', portanto, são estes os tratamentos que se destacam dos demais, por permitir a quebra da dormência e promover a germinação das sementes para todos os lotes utilizados. A eficiência destes tratamentos também foi observada nos resultados obtidos pelo IVG (Quadro 3).

Apesar dos resultados observados no método Ácido 15', a metodologia de superação da dormência de sementes de uma espécie deve ser determinada, levando-se em conta, também, a sua praticidade e o seu custo. O uso de ácido sulfúrico apresenta riscos como queimaduras, necessidade de um local apropriado para o seu descarte, além da dificuldade de empregá-lo em larga escala, devido aos cuidados necessários à sua aplicação e ao custo, quando comparado ao tratamento que utiliza água. Assim, a utilização do tratamento Água I torna-se vantajosa tanto pela eficiência na superação da dormência, quanto pela praticidade pelo custo.

Os resultados obtidos com o tratamento Água I estão de acordo com aqueles recomendados por Davide et al. 
(1995). Para Figliolia \& Silva (1982), o tratamento mostrou-se eficiente, porém com a imersão das sementes de canafístula por 2, 3 e 5 minutos. Já para Salerno et al. (1996), a eficiência do tratamento foi conseguida com 18 horas de imersão. Esse tratamento foi testado sem sucesso por Bianchetti e Ramos (1982), em sementes dessa espécie.
A diferença de resultados encontrados entre os autores, para o tratamento que utiliza ácido sulfúrico e água quente, pode ser devido às variações genéticoambientais entre os lotes utilizados. Alguns autores observaram que espécies com ampla distribuição geográfica podem responder diferentemente aos tratamentos utilizados, devido aos efeitos de adaptação e origem

Quadro 1 - Porcentagem média de sementes duras (SD), sementes mortas (SM), plântulas normais (PN) e plântulas anormais (PA) obtidas no teste de germinação para os diferentes tratamentos de quebra de dormência em sementes de canafístula (Peltophorum dubium (Sprengel) Taubert)

Table 1 - Mean germination percentage of hard seeds (SD), dead seeds (SM), and normal seedlings (PN) and abnormal plants (PA) of Peltophorum dubium (Sprengel) Taubert, submitted to dormancy breaking treatments

\begin{tabular}{|c|c|c|c|c|c|}
\hline Lote & Tratamento & $\mathrm{SD}(\mathrm{HS})$ & SM (DS) & PN (NS) & PA (AS) \\
\hline \multirow{5}{*}{ Lavras 1986} & Testemunha & 81 & 11 & $4 \mathrm{~B}$ & 4 \\
\hline & Ácido 30' & 0 & 100 & $0 \mathrm{~B}$ & 0 \\
\hline & Lixa & 0 & 45 & $50 \mathrm{~A}$ & 5 \\
\hline & Ácido 15' & 0 & 41 & $57 \mathrm{~A}$ & 2 \\
\hline & Água quente & 0 & 48 & $44 \mathrm{~A}$ & 8 \\
\hline \multirow{5}{*}{ Lavras1998 } & Testemunha & 50 & 2 & $46 \mathrm{C}$ & 2 \\
\hline & Ácido 30' & 0 & 97 & $3 \mathrm{D}$ & 0 \\
\hline & Lixa & 0 & 6 & $91 \mathrm{~A}$ & 3 \\
\hline & Ácido 15' & 0 & 21 & $76 \mathrm{AB}$ & 3 \\
\hline & Água quente' & 0 & 23 & $72 \mathrm{~B}$ & 5 \\
\hline
\end{tabular}

Médias seguidas pela mesma letra na coluna não diferem entre si pelo teste de Tukey, a $5 \%$.

Quadro 2 - Resultados médios do teste de germinação (plântulas normais) em sementes de canafístula (Peltophorum dubium (Sprengel) Taubert), para os diferentes métodos de quebra de dormência, desinfestação e lotes

Table 2 - Mean germination percentage of canafistula seeds, submitted to dormancy breaking and disinfection treatments

\begin{tabular}{|c|c|c|c|c|c|}
\hline \multirow{2}{*}{ Lote } & \multirow{2}{*}{ Dormência } & \multicolumn{3}{|c|}{ Desinfestação } & \multirow{2}{*}{ Testemunha } \\
\hline & & Polyfluanide & Hipoclorito & Benomyl & \\
\hline \multirow{5}{*}{ Lavras 1986} & Água I & $78 \mathrm{~A} \mathrm{a}$ & $67 \mathrm{~A} \mathrm{a}$ & $67 \mathrm{~A} \mathrm{a}$ & $69 \mathrm{~A} \mathrm{a}$ \\
\hline & Ácido 15' & $59 \mathrm{~A} \mathrm{a}$ & $63 \mathrm{Aa}$ & $62 \mathrm{~A} \mathrm{a}$ & $45 \mathrm{~A} \mathrm{a}$ \\
\hline & Ácido 17' & $71 \mathrm{Aa}$ & $45 \mathrm{~B} \mathrm{a}$ & $67 \mathrm{AB}$ a & $55 \mathrm{AB}$ a \\
\hline & Ácido 20' & $65 \mathrm{Aa}$ & $68 \mathrm{Aa}$ & $62 \mathrm{~A} \mathrm{a}$ & $50 \mathrm{~A} \mathrm{a}$ \\
\hline & Água II & $0 \mathrm{Ab}$ & $0 \mathrm{Ab}$ & $0 \mathrm{Ab}$ & $0 \mathrm{Ab}$ \\
\hline \multirow{5}{*}{ Lavras 1998} & Água I & $90 \mathrm{Aa}$ & $95 \mathrm{Aa}$ & $93 \mathrm{~A} \mathrm{a}$ & $91 \mathrm{Aa}$ \\
\hline & Ácido 15' & $85 \mathrm{~A} \mathrm{a}$ & $84 \mathrm{~A} \mathrm{a}$ & $96 \mathrm{~A} \mathrm{a}$ & $86 \mathrm{~A} \mathrm{a}$ \\
\hline & Água II & $16 \mathrm{Ab}$ & $14 \mathrm{Ab}$ & $8 \mathrm{Ab}$ & $12 \mathrm{Ab}$ \\
\hline & Ácido 17' & $0 \mathrm{Ac}$ & $0 \mathrm{Ac}$ & $0 \mathrm{~A} \mathrm{bc}$ & $0 \mathrm{Ac}$ \\
\hline & Ácido 20' & $0 \mathrm{Ac}$ & $0 \mathrm{Ac}$ & $0 \mathrm{Ac}$ & $0 \mathrm{Ac}$ \\
\hline \multirow{5}{*}{ Lins 1998} & Água I & $92 \mathrm{Aa}$ & $80 \mathrm{~A} \mathrm{a}$ & $94 \mathrm{~A} \mathrm{a}$ & $92 \mathrm{~A} \mathrm{a}$ \\
\hline & Ácido 15' & $84 \mathrm{~A} \mathrm{a}$ & $64 \mathrm{AB}$ a & $60 \mathrm{~B} \mathrm{~b}$ & $80 \mathrm{AB}$ ab \\
\hline & Ácido 17' & $87 \mathrm{~A} \mathrm{a}$ & $70 \mathrm{AB}$ a & $60 \mathrm{~B} \mathrm{~b}$ & $59 \mathrm{~B} \mathrm{~b}$ \\
\hline & Ácido 20' & $5 \mathrm{AB} \mathrm{b}$ & $16 \mathrm{~A} \mathrm{~b}$ & $6 \mathrm{AB} \mathrm{c}$ & $0 \mathrm{~B} \mathrm{c}$ \\
\hline & Água II & $0 \mathrm{~A} \mathrm{~b}$ & $1 \mathrm{Ac}$ & $0 \mathrm{~A} \mathrm{c}$ & $0 \mathrm{~A} \mathrm{c}$ \\
\hline
\end{tabular}

Médias seguidas pela mesma letra maiúscula nas linhas e minúscula nas colunas não diferem entre si pelo teste de Tukey, a 5\% de probabilidade. 
Quadro 3 - Índice de velocidade de germinação (IVG) em lotes de sementes de canafístula (Peltophorum dubium (Sprengel) Taubert), para os diferentes tratamentos utilizados

Table 3 - Speed of germination of canafistula seed batches, submitted to dormancy breaking treatments

\begin{tabular}{|l|c|c|c|}
\hline \multirow{2}{*}{ Tratamento } & \multicolumn{3}{|c|}{ Lote } \\
\cline { 2 - 4 } & Lavras1986 & Lavras1998 & Lins1998 \\
\hline Água I & $1,52 \mathrm{~A}$ & $2,90 \mathrm{~A}$ & $1,55 \mathrm{~A}$ \\
Ácido 15' & $1,11 \mathrm{AB}$ & $3,63 \mathrm{~A}$ & $2,09 \mathrm{~A}$ \\
Ácido 17' & $0,77 \mathrm{~B}$ & $0,00 \mathrm{C}$ & $1,52 \mathrm{~A}$ \\
Ácido 20' & $0,28 \mathrm{C}$ & $0,00 \mathrm{C}$ & $0,01 \mathrm{~B}$ \\
Água II & $0,00 \mathrm{D}$ & $0,30 \mathrm{~B}$ & $0,00 \mathrm{~B}$ \\
\hline
\end{tabular}

Médias seguidas pela mesma letra nas linhas não diferem entre si pelo teste de Tukey, a 5\% de probabilidade.

(Bianchetti, 1991; Jesus \& Piña-Rodrigues, 1991; Maluf, 1992; Schatral \& Fox, 1994; Allen \& Meyer, 1998; Andersson \& Milberg, 1998). Deste modo, na adaptação de metodologia de um teste, torna-se recomendável a utilização de sementes de vários anos e locais de coleta.

Em relação ao estudo de desinfestação, os principais fungos encontrados durante o teste de germinação das sementes de canafístula dos lotes estudados foram Trichoderma sp., Penicillium sp., Aspergillus niger e Fusarium sp., que segundo Mucci \& Lasca (1986) podem causar danos às sementes de canafístula. Entretanto, a porcentagem de sementes infestadas não comprometeu a germinação das sementes dos lotes testados

De acordo com o Quadro 2, nos tratamentos de desinfestação testados foi verificado que para o lote Lavras1986 apenas no tratamento Ácido 17' houve diferença significativa, devendo ser ressaltado que o tratamento com Polyfluanide foi estatisticamente diferente do tratamento hipoclorito. Já para o lote Lavras1998, não foram observadas diferenças significativas entre os tratamentos utilizados. Para o lote Lins1998, nos tratamentos Água I e Água II, não foram observadas diferenças significativas. Nos tratamentos Ácido 15' e Ácido 17', os melhores resultados foram alcançados com o tratamento Polyfluanide, enquanto no tratamento Ácido 20' o tratamento mais eficiente foi hipoclorito.

O uso de fungicidas para desinfestação foi desnecessário quando o tratamento utilizado foi Água I.
Neste tratamento, o porcentual de germinação obtido no tratamento- testemunha não diferiu estatisticamente dos demais. Desta forma, além do fácil acesso e da aplicação simples e relativamente segura em termos de possíveis acidentes de trabalho, o tratamento Água I dispensa o uso de qualquer tratamento adicional de desinfestação de patógenos.

\section{CONCLUSÃ̃o}

O tratamento de imersão das sementes de canafístula em água quente $\left(95^{\circ} \mathrm{C}\right)$ e posterior permanência na mesma água por 24 horas, fora do aquecimento, é eficiente na promoção da germinação, sendo prático e dispensando o uso de tratamentos de desinfestação.

\section{REFERÊNCIAS BIBLIOGRÁFICAS}

ALCALAY, N.; AMARAL, D. M. I. Descrição de plântulas de algumas essências florestais de interesse econômico para o Rio Grande do Sul. Roessléria, v. 4, n. 1, p. 85-100, 1981.

ALLEN, P. S.; MEYER, S. E. Ecological aspects of seed dormancy loss. Seed Science Research, v. 8, n. 2, p. 183191, 1998.

ANDERSSON, L.; MILBERG, P. Variation in seed dormancy among mother plants, populations and years of seed collection. Seed Science Research, v. 8, n. 1, p. 2938, 1998.

BEWLEY, J. D.; BLACK, M. Seeds: physiology of development and germination. New York: Plenum Press, 1994. $445 \mathrm{p}$.

BIANCHETTI, A. Tratamentos pré-germinativos para sementes florestais. In: SIMPÓSIO BRASILEIRO SOBRE SEMENTES FLORESTAIS, 2., 1989, Atibaia. Anais... São Paulo: Instituto Florestal, 1991. p. 237-246.

BIANCHETTI, A.; RAMOS, A. Comparação de tratamentos para superar a dormência de sementes de canafístula Peltophorum dubium (Spreng.) Taubert.

Boletim de Pesquisa Florestal, n. 4, p. 91-99, 1982.

BIANCHETTI, A.; RAMOS, A. Quebra de dormência de sementes de canafístula Peltophorum dubium (Spreng.) Taubert resultados preliminares. Boletim de Pesquisa Florestal, n. 3, p. 87-95, 1981. 
BRASIL. Ministério da Agricultura. Regras para análise de sementes. Brasília: 1992. 365 p.

van der BURG, W. J. et al. Predicting tomato seedling morphology by X-ray analysis of seeds. Journal American Society for Horticultural Science, v. 119, n. 2, p. 258-263, 1994.

CAPELANES, T. M. C. Quebra-de-dormência em sementes florestais, em laboratório. In: SIMPÓSIO BRASILEIRO SOBRE TECNOLOGIA DE SEMENTES FLORESTAIS, 2., 1991, Atibaia. Anais... São Paulo: Instituto Florestal, 1991. p. 41.

DAVIDE, A. C.; FARIA, J. M. R.; BOTELHO, S. A. Propagação de espécies florestais. Belo Horizonte: CEMIG; Lavras: UFLA, 1995. 41 p.

FERREIRA, F. A. Patologia florestal: principais doenças florestais no Brasil. Viçosa: Sociedade de Investigações Florestais, 1989. $570 \mathrm{p}$.

FIGLIOLIA, M. B.; SILVA, A. Germinação de sementes beneficiadas e não beneficiadas de Peltophorum dubium (Spreng.) Taubert. em laboratório e viveiro sob tratamentos pré-germinativos. In: CONGRESSO NACIONAL SOBRE ESSÊNCIAS NATIVAS, 1982, Campos do Jordão. Anais... Campos do Jordão: Instituto Florestal, 1982; Silvicultura em São Paulo, v. 16 A, pt. 2, p. 908-916, 1982.

GUERRA, M. P. et al. Comportamento da canafístula (Peltophorum dubium (Sprengel) Taubert) em viveiro, submetida a diferentes métodos de quebra de dormência e semeadura. Boletim de Pesquisa Florestal, n. 5, p. 1-15, 1982.

INSTITUTO BRASILEIRO DE GEOGRAFIA E ESTATÍSTICA - IBGE. Enciclopédia dos municípios brasileiros. Rio de Janeiro: 1995. 411 p.
JESUS, R. M.; PINÃ-RODRIGUES, F. C. M. Programa de produção e tecnologia de sementes florestais da Floresta Rio Doce S.A. : uma discussão dos resultados obtidos. In: SIMPÓSIO BRASILEIRO SOBRE SEMENTES FLORESTAIS, 2., 1989, Atibaia. Anais... São Paulo: Instituto Florestal, 1991. p. 59-86.

MAGUIRE, J. D. Speed of germination-aid in selection and evaluation for seedling emergence and vigor. Crop Science, v. 2, n. 1, p. 176-177, 1962.

MALUF, A. M. Variação populacional na germinação e dormência de sementes de Senna multijuga. In: CONGRESSO NACIONAL SOBRE ESSÊNCIAS NATIVAS, 2., 1992, São Paulo. Anais... São Paulo: Instituto Florestal, 1992. p. 728-732.

MUCCI, F. E. S.; LASCA, C. C. Flora fúngica de sementes de essências florestais nativas. Fitopatologia Brasileira, v. 11, n. 2, p. 352, 1986.

OLIVEIRA, L. M. Avaliação da qualidade de sementes de canafístula (Peltophorum dubium (Sprengel) Taubert) pelos testes de germinação, tetrazólio e raios-X. 2000. 111 f. Dissertação (Mestrado em Engenharia Florestal) Universidade Federal de Lavras, Lavras, 2000.

SALERNO, A. R.; SHALLENBERGER, T. C. H.; STUKER, H. Quebra de dormência em sementes de canafístula. Agropecuária Catarinense, v. 9, n. 1, p. 9-11, 1996.

SCHATRAL, A.; FOX, J. E. D. Quality and viability of seeds in the genus Hibbertia. Seed Science and Technology, v. 22, n. 2, p. 273-284, 1994.

TODD-BOCKARIE, A. H. et al. Pretreatment to overcome seed coat dormancy in Cassia sieberiana. Seed Science and Technology, v. 21, n. 2, p. 383-398,1993. 